\title{
Targeting the PI3K/PTEN/AKT/mTOR Pathway in Treatment of Sarcoma Cell Lines
}

\author{
HUI JUN LIM, XIAOCHUN WANG, PHILIP CROWE, DAVID GOLDSTEIN and JIA-LIN YANG \\ Sarcoma and Nano-oncology Group, Adult Cancer Program, Lowy Cancer Research Centre, \\ Department of Medical Oncology and Surgery, Prince of Wales Clinical School, \\ Faculty of Medicine, University of New South Wales, Randwick, NSW, Australia
}

\begin{abstract}
Background/Aim: Sarcoma carries a poor prognosis prompting the need for targeted therapies aimed at deregulated signaling pathways. These include the PI3K/Akt/mTOR pathway commonly up-regulated in malignancies attributed to loss of PTEN expression. However, PTEN status and activation state of PI3K/Akt/mTOR pathway have not been comprehensively studied in sarcoma. The aims of this study were to characterise PTEN and Akt expression in a panel of sarcoma cell lines and then to examine mTOR inhibition using ridaforolimus. Materials and Methods: PTEN genomic expression was analyzed using Sanger sequencing. PTEN, total Akt (tAkt) and phosphorylated Akt (pAkt) expression were quantified with western blot analysis. Antiproliferative effects of treatment regimens were designed using Chou \& Talalay's isobologram and determined with crystal violet assay. Results: Four cell lines had wild-type PTEN (exons 2 to 8), with normal protein expression. The GCT cell line had a missense mutation in exon $6(C>T)$, associated with loss of PTEN protein expression. Increased pAkt expression was found in all cell lines following epidermal growth factor (EGF) stimulation, indicating that wild-type PTEN expression in four cell lines did not inhibit constitutive activation of PI3K/Akt/mTOR pathway. Nonetheless, all cell lines demonstrated sensitivity to ridaforolimus within a clinically relevant dose-range (half-maximal inhibitory concentration $\left.\left(I C_{50}\right)=0.7-10 \quad n M\right)$. Conclusion: PTEN mutation is rare in sarcoma cell lines and constitutive activation of PI3K/Akt/mTOR is independent of PTEN status.
\end{abstract}

This article is freely accessible online.

Correspondence to: Jia-Lin Yang, Lowy Cancer Research Centre, Room 209, Faculty of Medicine, UNSW, Sydney, NSW 2052, Australia. Tel: +61 293859390, Fax: +61 293851510, e-mail: j.yang@unsw.edu.au

Key Words: Sarcoma, PI3K/PTEN/Akt/mTOR pathway, PTEN expression, targeted therapy.
Targeted inhibition with ridaforolimus monotherapy is a promising avenue to further investigate in sarcoma treatment. Sarcomas are a heterogeneous group of mesenchymal malignancies with more than 70 different subtypes $(1,2)$. Despite advances in its classification and pathogenesis, cytotoxic chemotherapy remains the standard-of-care for most sarcomas where the overall 5-year survival rate is $50 \%$ (3). In addition to their poor prognosis, chemotherapeutic regimens are associated with significant toxicity (4). There remains an urgent need for novel targeted therapies to improve clinical outcomes and tolerability in sarcoma treatment.

To develop effective targeted therapies, several key signaling pathways have attracted interest over the past decade and have been identified as potential treatment targets in sarcoma. These include epidermal growth factor receptor (EGFR) and its downstream signaling pathways, including the $\mathrm{PI} 3 \mathrm{~K} / \mathrm{AKT} / \mathrm{mTOR}$ cascade $(5,6)$. EGFR is commonly overexpressed in sarcoma and is an independent prognostic indicator of disease progression and overall survival $(7,8)$. In addition, its downstream pathways are constitutively activated in tumourigenesis, providing continuous signal transduction leading to increased cell growth and division (9-11). Notably, aberrant activation of $\mathrm{PI} 3 \mathrm{~K} / \mathrm{AKT} / \mathrm{mTOR}$ signaling is commonly attributed to phosphatase and tensin homologue (PTEN) dysfunction, which is an essential tumour suppressor gene that acts as a central negative regulator of the pathway (12, 13). Although PTEN dysfunction and constitutive activation of the PI3K/Akt/mTOR pathway have been wellestablished in epithelial and haematological cancers, limited studies are available in sarcoma $(14,15)$. Given their vital roles in oncogenesis, there is a strong basis for further examination of PTEN expression and activation state of PI3K/Akt/mTOR pathway in sarcoma. Moreover, mTOR inhibition is a potential approach to impede constitutive activation of PI3K/Akt/mTOR pathway. Hence, the aims of this study are to characterise the genomic status and protein expression of PTEN, in conjunction with Akt protein expression, in a panel of sarcoma cell lines. In addition, the growth inhibitory effects of ridaforolimus (mTOR inhibitor) will be determined. 
Table I. Primers for PCR and PTEN Sanger sequencing.

\begin{tabular}{lrcr}
\hline Exon & Forward Primer & Reverse Primer & PCR Product Size (bp) \\
\hline 2 & 5'-TGACCACCTTTTATTACTCCAGCTA-3' & 5'-ATCACACTGTAATGGAATCCAGGTA-3' & 512 \\
3 & 5'-TGAAAAGCTCTGGTTTTACTTCAGAT-3' & 5'-AAGTAACATGAATCTGTGCCAACA-3' & 510 \\
4 & 5'-AGTACTCTGTATTAGTGGCATCACA-3' & 5'-ATCTCACTCGATAATCTGGATGACT-3' & 423 \\
5 & 5'-CCAGTCCGTATAGCGTAAATTCCCA-3' & 5'-TCTCAGATCCAGGAAGAGGAAAGGA-3' & 562 \\
6 & 5'-GGCTACGACCCAGTTACCAT-3' & 5'-GGGCTGTATTTGGTGGTTATAACA-3' & 500 \\
7 & 5'-TTTGCTTGAGATCAAGATTGCAGAT-3' & 5'-ATGTTACAATGCCATAAGGCCTTT-3' & 504 \\
8 & 5'-TGCAAATGTTTAACATAGGTGACAGA-3' & 5'-TTTTGACGCTGTGTACATTGGGTAT-3' & 521 \\
\hline
\end{tabular}

\section{Materials and Methods}

Cell lines. Five human sarcoma cell lines were used for this study, representing different pathological subtypes: liposarcoma (778 and 449B), fibrosarcoma (HT1080), synovial sarcoma (SW982) and malignant fibrous histiocytoma (GCT). All cell lines were purchased from American Type of Cell Culture (Manassas, VA, USA) and validated by CellBank, Australia (www.cellbankaustralia.com.au). Cell lines were maintained in RPMI 1640 (Invitrogen, Carlsbad, CA, USA) supplemented with $2 \mathrm{mM} \mathrm{L-Glutamine,} 50$ units $/ \mathrm{ml}$ penicillin, $50 \mu \mathrm{g} / \mathrm{ml}$ streptomycin and $10 \%$ fetal bovine serum at $37^{\circ} \mathrm{C}$ in $5 \% \quad \mathrm{CO}_{2}$ atmosphere and demonstrated to be free of mycoplasma contamination.

Drug inhibitors. Stock solutions of $10 \mathrm{mM}$ for ridaforolimus (mTOR inhibitor) were prepared in dimethyl sulfoxide (DMSO) and stored in aliquots at $-20^{\circ} \mathrm{C}$. Ridaforolimus was purchased from SelleckChem (Sydney, Australia).

DNA extraction. DNA was extracted from each cell line using QIAamp DNA Mini Kit (Qiagen, Valencia, CA, USA) according to manufacturer's protocol. Concentration and purity of extracted DNA were determined using NanoDrop ND-1000 spectrophotometer (Thermo Fisher Scientific, Roskilde, Denmark); A260/280 ratio for cell lines were between 1.80-1.90.

Polymerase chain reaction (PCR). PCR amplification of humanspecific PTEN exons 2 to 8 was performed on C1000 Thermal Cycler (Invitrogen) using seven pairs of primers (Table I). Primer pairs were chosen in intronic regions of PTEN and designed with OligoPerfect Designer software (Invitrogen), using the reference sequence from the National Center for Biotechnology Information (NM_000314.4). PCR reactions were performed in $50 \mu$ l containing $100 \mathrm{ng}$ of genomic DNA, $0.2 \mu \mathrm{M}$ of oligonucleotide primers (Invitrogen) and $45 \mu \mathrm{l}$ of Platinum PCR SuperMix (Invitrogen). Thermocycling parameters were an initial denaturation at $94^{\circ} \mathrm{C}$ for $2 \mathrm{~min}$, followed by denaturation at $94^{\circ} \mathrm{C}$, annealing at $55^{\circ} \mathrm{C}$ and extension at $72^{\circ} \mathrm{C}$ for $30 \mathrm{~s}$ each and repeated for 35 cycles. This was followed by a final extension at $72^{\circ} \mathrm{C}$ for $10 \mathrm{~min}$. The integrity and specificity of PCR samples were verified by agarose gel electrophoresis on $1 \%$ agarose gel containing GelRed ${ }^{\mathrm{TM}}$ (Biotium, Inc., Hayward, CA, USA). The gel was electrophoresed with $0.5 \%$ TBE buffer for $30 \mathrm{~min}$ at $100 \mathrm{~V}$. High-quality PCR samples (Figure 1) were subsequently sent for sequencing following purification. For purification of PCR products, $5 \mu \mathrm{l}$ of a 1:15 dilution of ExoSAP-IT
Table II. Mean half-maximal inhibitory concentration $\left(I C_{50}\right)$ of ridaforolimus in sarcoma cell lines.

\begin{tabular}{lcc}
\hline Cell Line & Sarcoma Subtype & Ridaforolimus (nmol/1) \\
\hline 449B & Liposarcoma & 4.9 \\
778 & Liposarcoma & 5.2 \\
GCT & Malignant fibrous histiocytoma & 4.8 \\
HT1080 & Fibrosarcoma & 0.7 \\
SW982 & Synovial sarcoma & 0.8 \\
\hline
\end{tabular}

(USB, Cleveland, OH, USA) was added to each PCR sample and reactions were incubated at $37^{\circ} \mathrm{C}$ followed by inactivation at $80^{\circ} \mathrm{C}$ for 15 min each.

Sequencing of PTEN gene. Bi-directional Sanger sequencing of purified PCR products was performed at The Ramaciotti Centre for Gene Functional Analysis, University of New South Wales (Sydney, NSW, Australia) using an ABI 3730 Capillary Sequencer (Applied Biosystems, Darmstadt, Germany) and primers listed in Table I. Identified mutations were verified by bi-directional re-sequencing of original DNA sample.

Western blot analysis. Twenty-four hours after seeding in 6-well plates in culture medium, sarcoma cells were starved with medium containing $1 \%$ FBS for $24 \mathrm{~h}$. Cells were then harvested immediately after $15 \mathrm{~min}$ incubation with or without $100 \mathrm{ng} / \mathrm{ml}$ epidermal growth factor (EGF) (Sigma-Aldrich, Castle Hill, NSW, Australia) stimulation. Subsequently, protein extraction was conducted using radioimmunoprecipitation assay (RIPA) lysis buffer supplemented with $1 \%$ protease and phosphatase inhibitor cocktails (SigmaAldrich, Australia). Supernatants were collected and protein concentrations determined with BCA Protein Assay (Thermo Fisher Scientific). For Western blot analysis, whole cell lysate was mixed with an SDS protein gel loading solution (Sigma-Aldrich) and heated at $95^{\circ} \mathrm{C}$ for $5 \mathrm{~min}$. Forty $\mu \mathrm{g}$ of protein was loaded per well alongside a molecular marker (Cell Signalling, Danvers, MA, USA) in a 4-20\% Tris-glycine precast gel (Invitrogen) and electrophoresis was completed at $100 \mathrm{~V}$ for $60 \mathrm{~min}$, before being transferred to a polyvinylidene difluoride Hybond-P membrane (Amersham, Arlington Heights, IL, USA). Membrane was blocked by incubation with $5 \%$ skim milk at room temperature for $1 \mathrm{~h}$. Immunochemical 


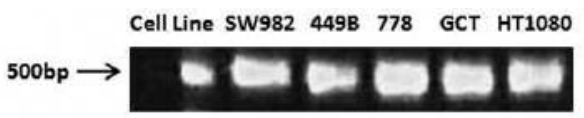

Figure 1. Polymerase chain reaction (PCR) samples (exon 7) visualised on $1 \%$ agarose gel. PCR products were assessed for specificity and quality by gel electrophoresis. PCR samples demonstrating a single band at the correct molecular weight were sent for sequencing. Representative image of PCR products containing exon 7 of PTEN is shown.

detection was performed using anti-PTEN rabbit monoclonal antibody $(1: 2,000$, Cell Signalling), anti-tAkt rabbit monoclonal antibody (1:5,000, Cell Signalling) and anti-pAkt rabbit monoclonal antibody (1:5,000, Cell Signalling), diluted in $5 \%$ bovine serum albumin (BSA), with overnight incubation at $4^{\circ} \mathrm{C}$. Subsequently, blots were incubated with horseradish peroxidise (HRP)-conjugated anti-rabbit secondary antibody $(1: 10,000$, Cell Signalling) at room temperature for $1 \mathrm{~h}$. HRP-conjugated secondary antibodies were detected by chemiluminescence agent SuperSignal Western Dura Extended Duration (Thermo Fisher Scientific). Target proteins on membrane were imaged with ImageQuant LAS4000 (GE healthcare, Uppsala, Sweden). Quantification of Western blots was performed by densitometry analysis with ImageQuant TL Software (GE Healthcare) and normalised to $\beta$-actin as loading control. Results were obtained from two independent experiments.

In vitro rug cytotoxic crystal violet assay (CVA). Viable sarcoma cells were checked by $0.2 \%$ trypan blue staining (Sigma-Aldrich) and, subsequently, seeded in a volume of $200 \mu \mathrm{l}$ at 3,000 cells/well in 96-well flat bottom plates. Following $24 \mathrm{~h}$, triplicate wells were treated with ridaforolimus each at 5 different doses for $72 \mathrm{~h}$ in culture medium (Invitrogen). Optimal dose range for each drug was decided through a series of pre-tests in our group in conjunction with literature data (16-19). Specifically, ridaforolimus was dissolved in DMSO and diluted with distilled water to concentrations at $0.01,0.1,1.0,10.0$ and $100 \mathrm{nM}$, respectively. DMSO was used as a vehicle control with a concentration corresponding to the highest drug concentration tested for each drug. Following $72 \mathrm{~h}$, cells were fixed with methanol and stained with $0.01 \%$ crystal violet (Sigma-Aldrich) for $15 \mathrm{~min}$ at room temperature, before being rinsed with three changes of distilled water until all excess stain was removed. The plate was left overnight to allow each well to air dry completely. Stained cells were then reabsorbed in a 1:1 mixture of $100 \%$ ethanol and $0.1 \mathrm{mM}$ sodium citrate. Cell viability was determined by measuring absorbance at $540 \mathrm{~nm}$ using SpectraMax Plus384 Absorbance Microplate Reader (Molecular Devices, Sunnyvale, CA, USA). Mean absorbance at $540 \mathrm{~nm}$ for each drug concentration was expressed as a percentage of the control well absorbance. Growth of experimentally-treated cells was compared to control cells:

Percentage of relative growth $=\left(\frac{\text { Mean optical density of treated cells }}{\text { Mean optical density of control cells }} \times 100\right) \%$

The percentage of relative inhibition following treatment was calculated as:

Percentage of relative inhibition $=(100-$ percentage of relative growth $) \%$

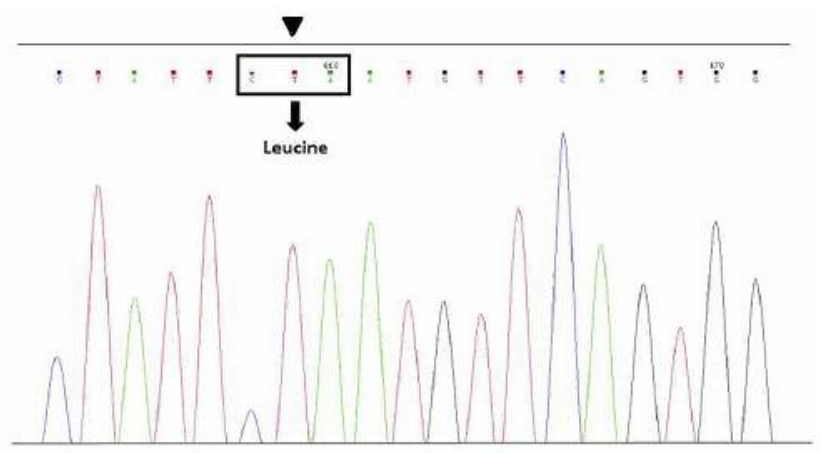

Figure 2. DNA sequencing electropherogram of exon 6 of PTEN in GCT (shown on sense strand). Sanger sequencing shows substitution of $C>T$ at bp 1642 of the PTEN gene (indicated by black arrow), potentially resulting in an amino acid change from glycine to leucine (aa 204).

The concentration at which cell viability was reduced to $50 \%$ of vehicle-treated controls (half maximal inhibitory concentration $\left(\mathrm{IC}_{50}\right)=$ median effective dose $\left.\left(\mathrm{ED}_{50}\right)\right)$ was determined using a sigmoidal curve fit with GraphPad Prism 6.0 (GraphPad Software, Inc., La Jolla, CA, USA). Experimental conditions were tested in two independent experiments with the samples in three replicates each.

\section{Results}

DNA sequencing of PTEN gene. To characterise the PTEN gene, genomic sequences of exons 2 to 8 of PTEN were compared with the wild-type $P T E N$ reference sequence obtained from the National Center for Biotechnology Information (NM_000314.4) using Sequencher software (Gene Codes Corporation, Ann Arbor, MI, USA), to screen for point mutations, insertions or deletions. Sequencing analysis revealed a homozygous point mutation $(\mathrm{C}>\mathrm{T})$ within the $P T E N$ protein coding region of exon 6 in a soft-tissue sarcoma (STS) cell line, GCT (Figure 2). This was a missense mutation that potentially resulted in a change from proline to leucine at amino acid 204. Apart from this finding, all other cell lines held no mutations, deletions or insertions from exons 2 to 8 . Duplicate experiments and sequencing were used to confirm the point mutation.

Akt protein expression. Total Akt (tAkt) and phosphorylated Akt (pAkt) expression in the presence or absence of EGF stimulation in sarcoma cell lines was examined to determine the activation state of PI3K/Akt/mTOR pathway. Based on densitometry analysis, tAkt and pAkt protein expression were quantified in cell lines with $\beta$-actin as loading control. In the absence of EGF, pAKT was detected in the majority of cell lines, with the exception of weak expression levels in SW982 and HT1080 (Figure 3). The expression of tAkt was present in all cell lines. Following EGF stimulation, pAkt expression levels were increased in all cell lines, while tAkt levels remained largely unchanged. 

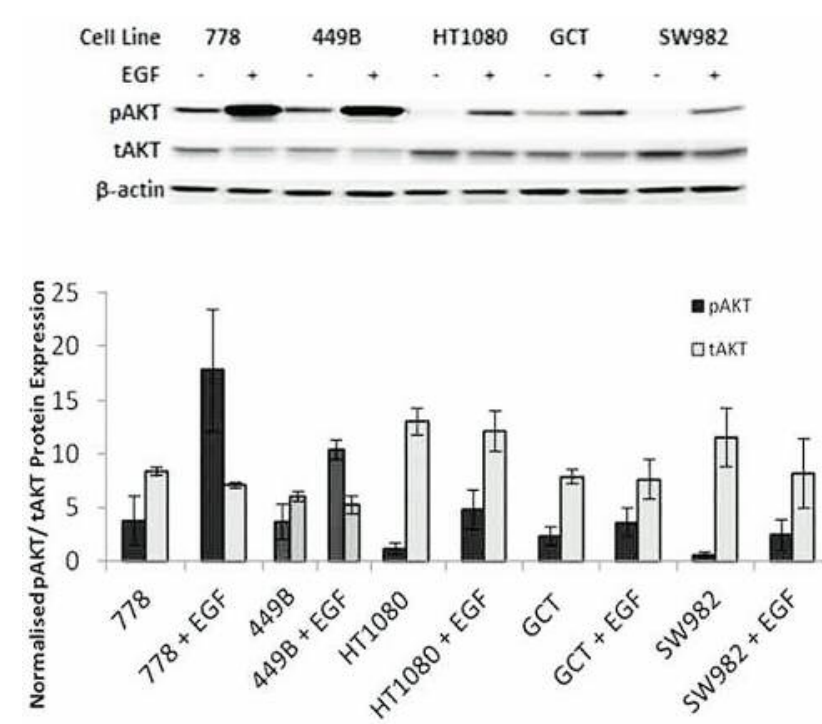

Figure 3. Western blot and densitometry analysis of Akt protein expression. In the absence of epidermal growth factor $(E G F)$ ligand stimulation, phosphorylated Akt (pAkt) was expressed in a majority of cell lines, with the exception of SW982 and HT1080. However, all cell lines demonstrated increased pAkt expression following EGF stimulation, indicating constitutive activation of PI3K/Akt/mTOR pathway. For densitometry analysis, bands were normalised to $\beta$-actin expression and quantified. Columns represent mean of 2 independent experiments and bars represent standard deviation. One representative blot out of duplicate experiments is shown.

PTEN protein expression. All sarcoma cell lines were assessed for PTEN protein expression by western blot analysis, with representative samples shown in Figure 4. Based on densitometry analysis, PTEN protein expression was quantified in each of the cell lines with $\beta$-actin as the loading control. In this study, 4 cell lines displayed normal PTEN expression, whereas 1 cell line (GCT) displayed loss of PTEN expression.

In vitro antiproliferative effects of monotherapy on sarcoma cell lines. The antiproliferative effects of monotherapy on a panel of 5 sarcoma cell lines were assessed using CVA following mTOR inhibition by ridaforolimus. The classification of sensitivity to drugs are based on therapeutically relevant ridaforolimus concentrations that are able to be achieved in serum from patients under treatment; these values have similarly been used in other studies to distinguish between sensitive and resistant cell lines. These values are $10 \mathrm{nM}$ for ridaforolimus (21-23). Profound sensitivity to ridaforolimus is defined as $\mathrm{IC}_{50}<1 \mathrm{nM}$, moderate sensitivity as $1 \mathrm{nM} \leq \mathrm{IC}_{50} \leq 10 \mathrm{nM}$, while $\mathrm{IC}_{50}>10 \mathrm{nM}$ demonstrates resistance. As shown in Figure 5, low nanomolar concentrations of ridaforolimus were found to suppress cellular proliferation in 5 cell lines examined. All cell lines were sensitive to ridaforolimus with a range of mean $\mathrm{IC}_{50}$
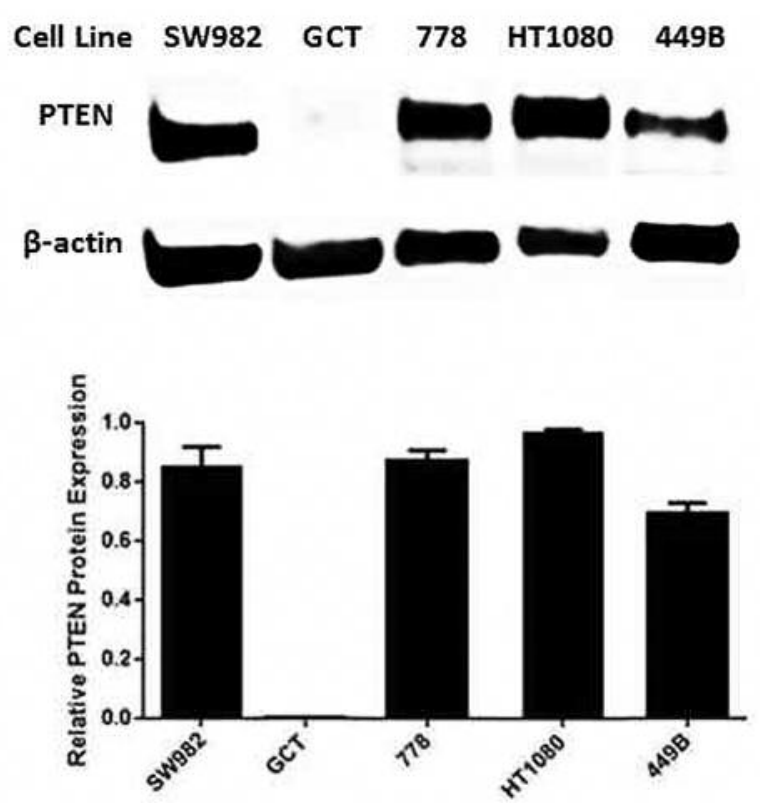

Figure 4. Western blot of PTEN protein expression. PTEN protein was expressed in 4 cell lines, while 1 cell line (GCT) had loss of PTEN expression. $\beta$-Actin was used as loading control. For densitometry analysis, bands were normalised to $\beta$-actin expression and quantified. Columns represent mean of 2 independent experiments and bars represent the standard deviation. One representative blot out of duplicate experiments is shown.

from $0.7 \mathrm{nM}$ to $5.2 \mathrm{nM}$ (Table II), suggesting that the mTOR inhibitor has potent growth-inhibitory effects on sarcoma cells.

\section{Discussion}

PTEN has been widely characterised in a range of malignancies providing further elucidation on their pathogenesis and progression (24-26). Conversely, PTEN has not been comprehensively examined in sarcoma. This study provided greater insight into the PTEN status in a panel of 5 sarcoma cell lines from various soft tissue subtypes (liposarcoma, fibrosarcoma, synovial sarcoma and malignant fibrous histiocytoma) and demonstrated that PTEN dysfunction is uncommon in sarcoma cell lines (1/5). In addition, wild-type PTEN in 4 cell lines and mutated PTEN in the GCT cell line were unable to inhibit activated PI3K/mTOR/Akt signaling, highlighting the potential utility of targeting this pathway. Given the lack of effective targeted therapies in sarcoma, this study provided preclinical evidence demonstrating the effectiveness of the mTOR inhibitor, ridaforolimus, on sarcoma cell growth inhibition $\left(\mathrm{IC}_{50}<10 \mathrm{nM}\right)$.

This study showed that PTEN mutation is rare in sarcoma cell lines and is not a major contributor to its dysfunction. Sequencing analysis revealed 1 out of the 5 cell lines, GCT, had 


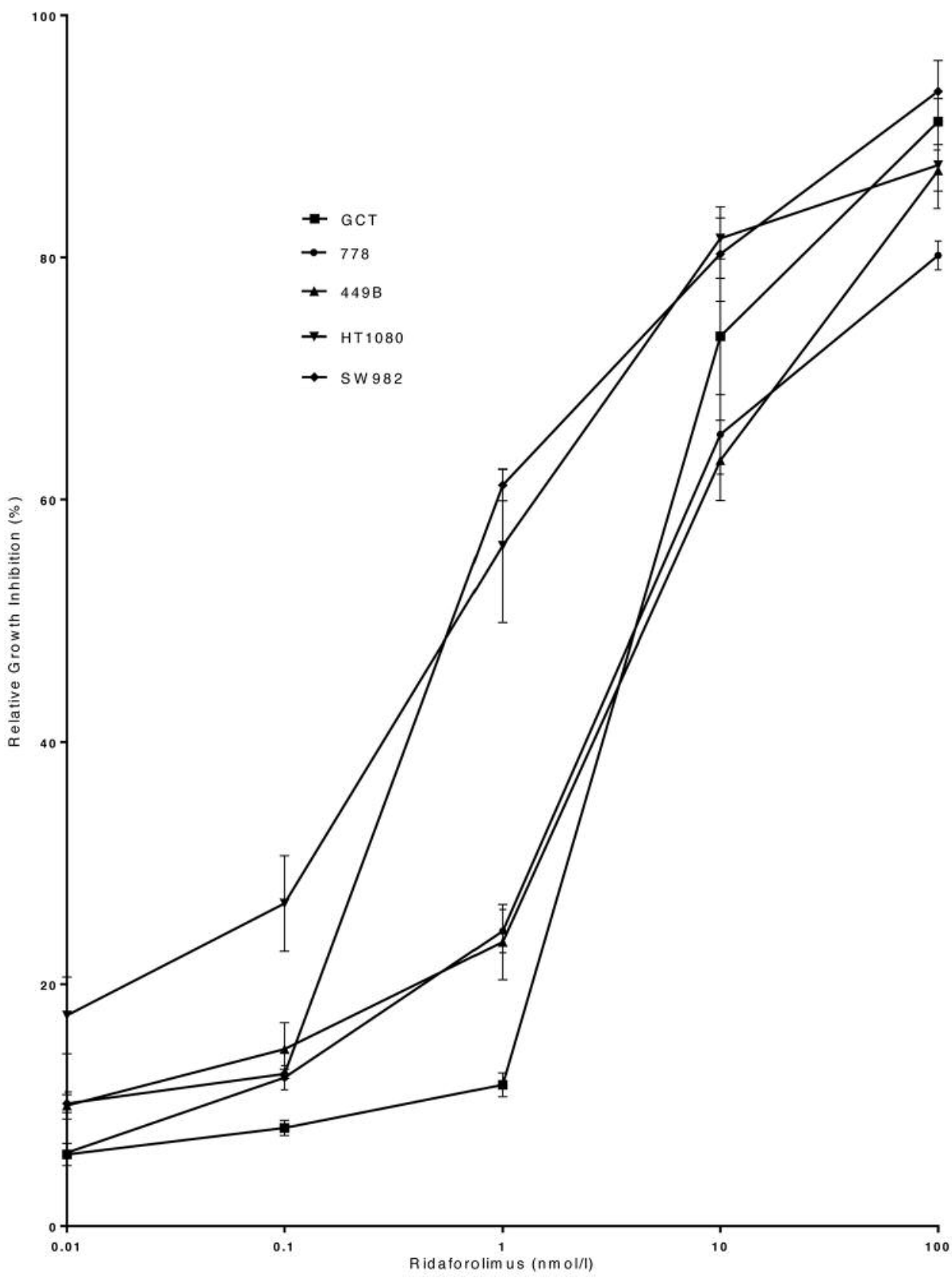

Figure 5. Dose-response curves of sarcoma cell lines. Dose-response curves of cell lines were a measure of the relative inhibition compared to vehicle control following treatment with ridaforolimus at varying ten-fold serial dilutions (0.01 nM, $0.1 \mathrm{nM}, 1 \mathrm{nM}, 10 \mathrm{nM}, 100 \mathrm{nM})$.

a biallelic missense mutation $(\mathrm{C}>\mathrm{T})$ in exon 6 of PTEN, which produces a change in the amino acid sequence from glycine to leucine (aa 204), and was associated with loss of PTEN protein expression. These findings are consistent with those of other studies, which have similarly shown PTEN gene alterations to be infrequent in sarcoma (27-29). For example, a study reported PTEN mutation was at a low rate of $2.3 \%$ in 86 STS tumour samples (30). Likewise, a separate study found a single PTEN mutation in only 1 of 40 samples of chondrosarcoma tumours (31). Further study of these infrequent mutations will be useful to identify alternative therapeutic strategies.

Sarcoma survival rates have reached a plateau in recent decades and there remains an urgent need to uncover novel targeted therapies to improve clinical outcomes $(32,33)$. Several deregulated signaling pathways in sarcoma have undergone intense study to develop effective drug inhibitors $(34,35)$. The 
$\mathrm{PI} 3 \mathrm{~K} / \mathrm{AKT} / \mathrm{mTOR}$ pathway was shown to be up-regulated in the panel of sarcoma cell lines examined, with increased expression of phosphorylated Akt. These findings indicate that, despite a majority of the cell lines expressing the wild-type PTEN gene, they are unable to inhibit signal transduction in the PI3K pathway. This may be attributed to other aberrant signalling components, including gain-of-function mutations in the PIK3CA gene, leading to constitutive activation of the $\mathrm{PI} 3 \mathrm{~K} / \mathrm{AKT} / \mathrm{mTOR}$ cascade (36). mTOR serves as a central regulator of cell growth and division as part of the PI3K pathway (37). Specifically, it has an essential role in facilitating progression through the cell cycle and enabling cell proliferation. Therefore, mTOR inhibition with ridaforolimus is a promising therapeutic option to impede PI3K/AKT/mTOR signalling contributing to cell survival and has demonstrated effective growth inhibition in the panel of sarcoma cell lines. Moreover, several cell lines (HT1080 and SW982) exhibited profound sensitivity to this targeted agent, with $\mathrm{IC}_{50}$ below 1 $\mathrm{nM}$. Likewise, multiple studies have demonstrated the potent antiproliferative effects of ridaforolimus and its ability to downregulate the PI3K/AKT/mTOR pathway $(38,39)$. A study reported low nanomolar concentrations of ridaforolimus suppressed cellular proliferation of 11 sarcoma cell lines (40). In addition, ridaforolimus was able to block mTOR signaling, as evidenced by a reduction in phosphorylation of downstream effectors, 4E-BP1 and ribosomal protein S6. Collectively, these results demonstrate the usefulness of mTOR inhibition as a potential treatment option in sarcoma. Moving forward, the therapeutic efficacy of ridaforolimus needs to be verified in in vivo models. Additionally, functional analysis of PTEN in sarcoma cell lines and tissue samples is necessary to verify its tumour suppressor activity.

With over 70 different histological sarcoma subtypes, the panel of STS and osteosarcoma cell lines used in this study represents a small proportion of these tumours. Future studies should target a large cohort of patient samples comprising a wide range of sarcoma subtypes to validate in vitro results of PTEN status and therapeutic efficacy of targeted agents. In addition, further examination into detailed molecular mechanisms of inhibition and synergistic antitumour effects of combination therapy could be undertaken in prospective studies. Nonetheless, this study provided strong support for the ongoing investigation of ridaforolimus as a therapeutic agent in sarcoma.

\section{Conclusion}

In conclusion, this study demonstrated that the PTEN mutation is rare in the panel of sarcoma cell lines examined and constitutive activation of $\mathrm{PI} 3 \mathrm{~K} / \mathrm{Akt} / \mathrm{mTOR}$ pathway is independent of PTEN status. In addition, mTOR inhibition was shown to be an attractive monotherapeutic intervention with broad antiproliferative activity in sarcoma cell lines.
Although the extrapolation of in vitro data to the clinical setting should be considered with caution, these results support the ongoing rational development of ridaforolimus and its analogues to obtain enhanced clinical outcomes in sarcoma treatment.

\section{References}

1 Toulmonde M, Bonvalot S, Méeus P, Stoeckle E, Riou O, Isambert N, Bompas E, Jafari M, Delcambre-Lair C, Saada E, Le Cesne A, Le Péchoux C, Blay JY, Piperno-Neumann S, Chevreau C, Bay JO, Brouste V, Terrier $\mathrm{P}$, Ranchère-Vince $\mathrm{D}$, Neuville A and Italiano A: Retroperitoneal sarcomas: patterns of care at diagnosis, prognostic factors and focus on main histological subtypes: a multicenter analysis of the French Sarcoma Group. Ann Oncol 25(3): 735-742, 2014.

2 Gibault L, Pérot G, Chibon F, Bonnin S, Lagarde P, Terrier P, Coindre JM and Aurias A: New insights in sarcoma oncogenesis: a comprehensive analysis of a large series of 160 soft tissue sarcomas with complex genomics. J Pathol 223(1): 64-71, 2011.

3 Italiano A, Mathoulin-Pelissier S, Cesne AL, Terrier P, Bonvalot S, Collin F, Michels JJ, Blay JY, Coindre JM and Bui B: Trends in survival for patients with metastatic soft-tissue sarcoma. Cancer 117(5): 1049-1054, 2011.

4 Cassier PA, Polivka V, Judson I, Soria JC, Penel N, Marsoni S, Verweij J, Schellens JH, Morales-Barrera R, Schöffski P, Voest EE, Gomez-Roca C, Evans TR, Plummer R, Gallerani E, Kaye SB and Olmos D: Outcome of patients with sarcoma and other mesenchymal tumors participating in phase I trials: a subset analysis of a European Phase I database. Ann Oncol 25(3): 44-58, 2014.

5 Chao J, Chow WA and Somlo G: Novel targeted therapies in the treatment of soft-tissue sarcomas. Expert Rev Anticancer Ther 10(8): 1303-1311, 2010.

6 Martín L, Laura LT, Miguel S, Silvia M, Xavier G and Oscar MT: Targeted Therapies in Sarcomas: Challenging the Challenge. Sarcoma 6(2): 13-20, 2012.

7 Yang JL, Romi DG, Ian WD and Philip JC: Potential application of EGFR targeted therapies in different types of sarcomas. AACR Meeting Abstracts 3(1): 292, 2006.

8 Teng HW, Wang HW, Chen WM, Chao TC, Hsieh YY, Hsih CH, Tzeng $\mathrm{CH}$, Chen $\mathrm{PC}$ and Yen $\mathrm{CC}$ : Prevalence and prognostic influence of genomic changes of EGFR pathway markers in synovial sarcoma. J Surg Oncol 103(8): 773-781, 2011.

9 Italiano A, Chen CL, Thomas R, Breen M, Bonnet F, Sevenet N, Longy M, Maki RG, Coindre JM and Antonescu CR: Alterations of the $\mathrm{p} 53$ and PIK3CA/AKT/mTOR pathways in angiosarcomas: a pattern distinct from other sarcomas with complex genomics. Cancer 118(23): 5878-5887, 2012.

$10 \mathrm{Wu} \mathrm{P}$ and $\mathrm{Hu}$ YZ: PI3K/Akt/mTOR pathway inhibitors in cancer: a perspective on clinical progress. Curr Med Chem 17(35): 43264341, 2010.

11 Bournazou E and Bromberg J: Targeting the tumor microenvironment: JAK-STAT3 signaling. JAK-STAT 2(2): 23-28, 2013.

12 Zhang XC, Piccini A, Myers MP, Van Aelst L and Tonks NK: Functional analysis of the protein phosphatase activity of PTEN. Biochem J 444(3): 457-464, 2012.

13 Hopkins BD, Hodakoski C, Barrows D, Mense SM and Parsons RE: PTEN function: the long and the short of it. Trends Biochem Sci 18(2): 58-67, 2014. 
14 Goy A, Hernandez-Ilzaliturri FJ, Kahl B, Ford P, Protomastro E and Berger M: A phase I/II study of the pan Bcl-2 inhibitor obatoclax mesylate plus bortezomib for relapsed or refractory mantle cell lymphoma. Leuk Lymphoma 128(43): 87-96, 2014.

15 Kwitkowski VE, Prowell TM, Ibrahim A, Farrell AT, Justice R, Mitchell SS, Sridhara R and Pazdur R: FDA approval summary: temsirolimus as treatment for advanced renal cell carcinoma. Oncologist 15(4): 428-35, 2010.

16 Ganjoo KN: New developments in targeted therapy for soft tissue sarcoma. Curr Oncol Rep 12(4): 261-265, 2010

17 Wang X, Goldstein D, Crowe PJ and Yang JL: S3I-201, a Novel STAT3 Inhibitor, Inhibits Growth of Human Soft Tissue Sarcoma Cell Lines. World J Cancer Res 1(1): 61-68, 2013.

18 Chernoguz A, Crawford K, Donovan E, Vandersall A, Berglund C, Cripe TP and Frischer JS: EGFR inhibition fails to suppress vascular proliferation and tumor growth in a Ewing's sarcoma model. J Surg Res 173(1): 1-9, 2012.

19 Sette G, Salvati V, Memeo L, Fecchi K, Colarossi C, Di Matteo P, Signore M, Biffoni M, D'Andrea V, De Antoni E, Canzonieri V, De Maria R and Eramo A: EGFR inhibition abrogates leiomyosarcoma cell chemoresistance through inactivation of survival pathways and impairment of CSC potential. PLoS One 7(10): 46891, 2012.

20 Imura Y, Yasui H, Outani H, Wakamatsu T, Hamada K, Nakai T, Yamada S, Myoui A, Araki N, Ueda T, Itoh K, Yoshikawa H and Naka N: Combined targeting of mTOR and c-MET signaling pathways for effective management of epithelioid sarcoma. Mol Cancer 13: 185, 2014.

21 Squillace RM, Miller D, Cookson M, Wardwell SD, Moran L, Clapham D, Wang F, Clackson T and Rivera VM: Antitumor activity of ridaforolimus and potential cell-cycle determinants of sensitivity in sarcoma and endometrial cancer models. Mol Cancer Ther 10(10): 1959-1968, 2011.

22 Meric-Bernstam F, Akcakanat A, Chen H, Do KA, Sangai T, Adkins F, Gonzalez-Angulo AM, Rashid A, Crosby K, Dong M, Phan AT, Wolff RA, Gupta S, Mills GB and Yao J: PIK3CA/PTEN mutations and Akt activation as markers of sensitivity to allosteric mTOR inhibitors. Clin Cancer Res 18(6): 1777-1789, 2012.

23 Glaysher S, Bolton LM, Johnson P, Torrance C and Cree IA: Activity of EGFR, mTOR and PI3K inhibitors in an isogenic breast cell line model. BMC Research Notes 7(1): 397, 2014.

24 Yang J, Ren Y, Wang L, Li B, Chen Y, Zhao W, Xu W, Li T and Dai F: PTEN mutation spectrum in breast cancers and breast hyperplasia J Cancer Res Clin Oncol 136(9): 1303-1311, 2010.

25 Hollander MC, Blumenthal GM and Dennis PA: PTEN loss in the continuum of common cancers, rare syndromes and mouse models. Nat Rev Cancer 11(4): 289-301, 2011.

26 Day FL, Jorissen RN, Lipton L, Mouradov D, Sakthianandeswaren A, Christie M, Li S, Tsui C, Tie J, Desai J, $\mathrm{Xu}$ ZZ, Molloy $\mathrm{P}$, Whitehall V, Leggett BA, Jones IT, McLaughlin S, Ward RL, Hawkins NJ, Ruszkiewicz AR, Moore J, Busam D, Zhao Q, Strausberg RL, Gibbs P and Sieber OM: PIK3CA and PTEN Gene and Exon Mutation-Specific Clinicopathologic and Molecular Associations in Colorectal Cancer. Clin Cancer Res 19(12): 3285-3296, 2013.

27 Saito T, Oda Y, Kawaguchi K, Takahira T, Yamamoto H, Tamiya S, Tanaka K, Matsuda S, Sakamoto A, Iwamoto $\mathrm{Y}$ and Tsuneyoshi M: PTEN/MMAC1 gene mutation is a rare event in soft tissue sarcomas without specific balanced translocations. Int J Cancer 104(2): 175-178, 2003.
28 Gibault L, Ferreira C, Pérot G, Audebourg A, Chibon F, Bonnin S, Lagarde P, Vacher-Lavenu MC, Terrier P, Coindre JM and Aurias A: From PTEN loss of expression to RICTOR role in smooth muscle differentiation: complex involvement of the mTOR pathway in leiomyosarcomas and pleomorphic sarcomas. Mod Pathol 25(2): 197-211, 2012.

29 Mueller S, Phillips J, Onar-Thomas A, Romero E, Zheng S, Wiencke JK, McBride SM, Cowdrey C, Prados MD, Weiss WA, Berger MS, Gupta N and Haas-Kogan DA: PTEN promoter methylation and activation of the $\mathrm{PI} 3 \mathrm{~K} / \mathrm{Akt} / \mathrm{mTOR}$ pathway in pediatric gliomas and influence on clinical outcome. Neuro Oncol 14(9): 1146-1152, 2012.

30 Yin L, Liu CX, Nong WX, Chen YZ, Qi Y, Li HA, Hu WH, Sun $\mathrm{K}$ and Li F: Mutational analysis of p53 and PTEN in soft tissue sarcoma. Mol Med Rep 5(2): 457-461, 2012.

31 Lin C, Meitner PA and Terek RM: PTEN mutation is rare in chondrosarcoma. Diagn Mol Pathol 11(1): 22-26, 2002.

32 Slomovitz BM and Coleman RL: The PI3K/AKT/mTOR Pathway as a Therapeutic Target in Endometrial Cancer Clin Cancer Res 24(4): 48-55, 2012.

33 Al-Zaid T, Somaiah N and Lazar AJ: Targeted therapies for sarcomas: new roles for the pathologist. Histopathology 64(1): 119-133, 2014.

34 Willems L, Tamburini J, Chapuis N, Lacombe C, Mayeux P and Bouscary D: PI3K and mTOR signaling pathways in cancer: new data on targeted therapies Curr Oncol Rep 14(2): 129-138, 2012.

35 Carracedo A and Pandolfi PP: The PTEN-PI3K pathway: of feedbacks and cross-talks. Oncogene 27(41): 5527-5541, 2013.

36 Steelman LS, Chappell WH, Abrams SL, Kempf RC, Long J, Laidler P, Mijatovic S, Maksimovic-Ivanic D, Stivala F, Mazzarino MC, Donia M, Fagone P,Malaponte G, Nicoletti F, Libra M, Milella M, Tafuri A, Bonati A, Bäsecke J, Cocco L, Evangelisti C, Martelli AM, Montalto G, Cervello M and McCubrey JA: Roles of the Raf/MEK/ERK and $\mathrm{PI} 3 \mathrm{~K} / \mathrm{PTEN} / \mathrm{Akt} / \mathrm{mTOR}$ pathways in controlling growth and sensitivity to therapy-implications for cancer and aging. Aging (Albany NY) 3(3): 192-222, 2011.

37 De Luca A, Maiello MR, D'Alessio A, Pergameno $M$ and Normanno N: The RAS/RAF/MEK/ERK and the PI3K/AKT signalling pathways: role in cancer pathogenesis and implications for therapeutic approaches. Expert Opin Ther Targets 16(S2): 17-27, 2012.

38 Blay JY: Updating progress in sarcoma therapy with mTOR inhibitors Ann Oncol 22(2): 280-287, 2011.

39 Mita MM, Gong J and Chawla SP: Ridaforolimus in advanced or metastatic soft tissue and bone sarcomas. Expert Rev Clin Pharmacol 6(5): 465-482, 2013.

40 Squillace RM, Miller D, Cookson M, Wardwell SD, Moran L, Clapham D, Wang F, Clackson T and Rivera VM: Antitumor activity of ridaforolimus and potential cell-cycle determinants of sensitivity in sarcoma and endometrial cancer. Models Mol Cancer Ther 10(10): 1959-1968, 2011.
Received July 12, 2016

Revised July 23, 2016

Accepted August 3, 2016 